\title{
How Teachers can Meet the Challenges of Sizable Classes and Student Disruptive Behavior
}

\author{
Dr. Youssef Mezrigui \\ Béja Higher Institute of Applied Languages and Computer Science, University of Jendouba, Tunisia \\ Email: mezriguiyuceph@yahoo.fr
}

\section{Doi:10.5901/jesr.2015.v5n2p107}

\begin{abstract}
The challenges of large classes and student classroom disruptive behavior have been a fact of life the world over. What has triggered examining both issues is that in the Tunisian context, little has seriously and wisely been devoted to them on the part of the parties concerned, namely inspectors, teacher trainers, administrators, and the relevant ministries (i.e., the Ministry of National Education and the Ministry of Higher Education and Scientific Research) with the object of dealing with them successfully. Relying on the author's analytical and critical reflections, as well as his personal experience as an instructor, and on that of some fellows, this paper aims at discussing these challenges and attempts to suggest drastic measures that could help teachers meet them. As concerns the former issue, the paper will explore the concept of a large class, the reasons behind its prevalence, the ensuing difficulties it poses to teachers, and how it could be turned into a blessing in disguise. Regarding students' disruptive conduct, the paper will look at the underlying causes of the frequency of the phenomenon and put forward a number of effective courses of action that could be taken to surmount it. On the other hand, this paper is meant to serve as an incentive for the aforementioned parties to attach paramount importance to sizable classes and student classroom misconduct, and have every intention of helping teachers manage both predicaments, and it may equally be utilized as a guide to assist them in achieving the same aim.
\end{abstract}

Keywords: large classes; student disruptive behavior; teachers; students

\section{Introduction}

Large classes and student disruptive behavior in all educational institutions have been the subject of a considerable amount of literature, generally by reason of their substantial connection with the field of education, and hence their impact on the teaching-learning process. Therefore, for the purpose of this paper, both issues are to be considered from a number of particular angles and from diverse standpoints.

Where a large class is concerned, there is some contention regarding its concept. Such contention generally lies, on the one hand, in some parties' view that what constitutes a large class depends on numerical size, and on the other hand, in other parties' conviction that the concept of the issue hinges on particular factors, such as the subjects taught and the usual number of groups of learners of whatever size one teacher is used to teaching. For instance, Kerr (2011, p. 2) points out that "defining what constitutes a large class [differs] according to the discipline, the level and nature of the class (such as introductory or upper year, lecture, tutorial or laboratory), and the perceptions of lecturers and individual students." Virtually, the same view is maintained by Todd (2006) who states that "what is taught influences teachers' judgments of the size of classes" (p. 1). In a similar frame of reference, Sulistyowati (2012) argues that "not all English teachers think that class size matters. Such teachers would say that good teaching is good teaching: what holds true for small classes also holds true for large ones." According to a teacher's guide on large classes by UNESCO (2006), "a large class has no 'exact size."' Ur (1996), in turn, does not restrict the size of a class to a specific number. She contends that "the exact number does not really matter: what matters is how you, the teacher, see the class size in your own specific situation" (p.302).

A number of other researchers, however, refer to or report teachers' and students' view of the concept on the basis of the number of learners enrolled in one class, or the average number of students registered at a particular educational institution. In the context of Canadian higher education, Jungic et al. (2006) define a large class as being composed of 350 students or more managed by one instructor. Hess (2001) notes that in china and Pakistan, where there are classes of more than sixty and over one hundred students respectively, a group of 35 or 40 learners is probably judged to be a one teacher small-sized class. 
Definitely, far more significant than the concept of a large class is examining its effects on the teaching output and the learning outcome, and how teachers can cope with it. In fact, it is often argued that large classes present challenges for both teachers and students. Broadly, where teachers are concerned, teaching a large class is physically tiring and psychologically annoying, which can impact detrimentally on the teaching effectiveness, and consequently - as far as learners are concerned - on the learning achievement expected, in the sense that, as Wolne (2011) points out, "the large class environment can result in poor learning, a pronounced sense of student anonymity that can leave them less motivated to study, and subsequently lower retention and graduation rates later on." Alongside these serious impediments, however, the author states that there do seem to be some real benefits to learners, instructors, and the university as a whole. Indeed, a large class setting can assist students in inculcating study skills that can serve them as they move forward with their education. A sizable class prompts them to be more responsible for their own learning as they will likely have less interaction with the teacher in that class. Regarding teachers, the author argues that the challenges of a large class hone some of the most basic skills of being a teacher, and reports that a number of instructors questioned about the issue asserted unanimously that teaching in the large class environment helped to make them better teachers overall, in both large and small class settings. Apropos of the benefit of large classes to the higher education institution, the writer explains that if they are done effectively, such classes are good business for the university in the sense that assigning one instructor to teach a class of 400 students is a more cost-effective educational instrument than having 4 instructors teaching a group of 100 students each. Jawitz (2013) voices a similar view in this regard contending that teaching a sizable class is economically beneficial, in that it can be very resource-efficient, since it represents important savings in terms of both expenses and time and effort spent in preparing lectures, communicating with students, and preparing and distributing information and resource documents.

Nonetheless, Cleveland (2002) does not seem to hold any opinion on any real benefits of teaching large groups of students, but in order for instructors to meet such a challenge, she maintains that they ought to develop and implement a teaching principle which resides mainly in the necessity of adopting a philosophy for teaching a large class that is not different from one for a small class, and avoiding to be discouraged by perceptual or emotional obstacles, but stretching their imagination and training themselves to be inventive, so as to foster their creative teaching skills.

One possible problematic result of large classes is student misbehavior, by reason of some teachers' inability to control such classes. Charles (1999) defines misbehavior as "behavior that is considered inappropriate for the setting or situation in which it occurs" (p. 2). It is generally agreed that the causes behind student misconduct are mainly emotional and psychological. Topper et al (1994) hold that students exhibit certain misbehaviors to satisfy particular needs. The authors list several needs met by students' inappropriate behaviors. Three remarkable misbehaviors exhibited by students are revenge, escape/avoidance, and play. Students behave revengefully to serve the need to punish someone who has harmed them, thus protecting themselves from possible, future harms. Concerning the second one, it serves the need to get rid of something the student does not desire. As for the third one, it aims to serve the need for amusement.

Doubtless, uncivil student behavior is a very serious predicament for all those concerned with the teachinglearning process. As is the case for large classes, much emphasis in the literature has, of course, been laid on how the parties involved, namely instructors and administrators can curb the phenomenon. Sorcinelli (1994) recommends that instructors define expectations at the outset. She suggests teachers ought to make good use of the first class for welcoming students and communicating expectations for classroom conventions, such as arriving, leaving, and talking in class. She makes it clear that "[t]he challenge lies in establishing both a pleasant atmosphere and a code of conduct." But, in case any troublesome behavior occurs, many of those who wrote on the issue stress the necessity of dealing with it promptly in the sense that, as Kuhlenschmidt and Layne (1999) warn, "if ignored or handled poorly, even a single act of incivility can have a long-term impact on classroom atmosphere", and add that "[such behavior] may escalate to intolerable or dangerous levels" (p.45).

In a similar setting, Epstein et al (2008) suggest a number of recommendations to deal with the issue. One recommendation consists in identifying the specifics of the problem behavior and the conditions that prompt and reinforce it. Another recommendation resides in modifying the classroom learning environment to decrease problem behavior. The authors equally recommend instructors to teach and reinforce new skills with the object of increasing appropriate conduct and preserve a positive classroom climate. Of no less importance is the authors' focus on the instructor's drawing on relationships with professional colleagues, students' families, and community behavior experts for continued guidance and support, by reason of the conviction that social relationships and collaborative opportunities can play a critical role in supporting teachers in managing student classroom disruptive behavior.

Ali and Gracey (2013) underscore the prerequisite role of an instructor-student relationship based on reciprocal respect in establishing a conflict-free learning environment. The authors propound some other strategies that, as they 
claim, may help in reducing or eliminating disruptions. These include: (a) addressing the student privately, respectfully and in a non-offending way, (b) attempting to take the steam out of the conversation; using a calm, non-confrontational voice, (c) explaining the effect of the disruptive behavior on the class, both as a whole and for individual students, (d) referring to rules regarding disruptive behavior (institutional and/or course rules), and (e) giving deadlines for improving or stopping the behavior.

\section{Large Classes}

As argued above, large classes are reckoned among the daunting challenges teachers face, particularly by reason of the problems they are very likely to pose to them.

\subsection{Defining a large class}

As stated in the Introduction, there is no definite definition of a large class. What is termed large class differs from one country to another and from one teacher to another in the same country. Certain parties relate the concept to various numbers of students, but others connect it with particular factors, such as personal convictions and the class size teachers in different countries are accustomed to teaching. Generally, in Tunisia the number of students in one class does matter. In this frame of reference, sixty Tunisian teachers from different secondary schools were asked how many students they think a large class includes. Twenty-one teachers believe that a large class consists of a number of students ranging from 20 to 25; thirty teachers think that the number of learners in a large class varies between 25 and 30 , whereas only nine teachers hold that a class of 30 to 35 individuals is large.

Hinging on the majority of answers, it could be affirmed that in Tunisia, a class of 30 students at most can be considered large, but a group of more than 35 learners may be reckoned to be very large.

Following from what is deliberated above, it could be maintained that what is behind the various viewpoints about the number of students making up a large group of learners is the teacher's being used to teaching a particular class size. For instance, the above-referred to opinions of the Tunisian teachers about the issue derives from the size of classes they have been accustomed to teaching, which ranges from 15 to 35 students per class. In this regard, Nolasco and Arthur (1994) roughly hold the very opinion claiming that "teachers who are used to groups of 12-14 students might find a group of 20 to be rather threatening" (p. 4). This would imply that the teacher is normally expected to cope with the situation whatever the class size is.

\subsection{What is behind large classes?}

There are particular factors which usually result in the prevalence of crowded classrooms in Tunisia. One reason is insufficient human resources. In fact, there has been a shortage of instructors, especially in the tertiary level, in particular in certain disciplines, like English as a foreign language. A related factor is financial. The Ministry of Higher Education cannot employ as many teachers as needed. Indeed, instead of recruiting two teachers, each of whom teaches a group of about twenty students, it recruits just one teacher to teach a class of forty students. There is also a logistical reason behind the issue. There is a marked lack of teaching space in many educational institutions, such as the Higher Institute of Applied Languages and Computer Science of Béja, where - during the current academic year - there are only nine classrooms, one lecture hall, and two laboratories intended for teaching English, Spanish, and German pronunciation.

\subsection{Challenges resulting from large classes}

Large classes present challenges, not only to the teacher, but also to students and their parents. Where the student is concerned, there is a general belief that learning in a crowded classroom is not as beneficial as learning in a small-sized class, where the learner can have more opportunities to take part in lessons, and the teacher can help everybody in the group. As for parents, they are often worried about the size of the class in which their children are enrolled. At the beginning of each school year, a number of my colleagues and I ask our children about the number of students in their classes, because of our conviction that they can achieve better school results in small classes than they can do in large classes. For the teacher's part, s/he is thought to suffer most from large classes. In fact, there is a common negative attitude among teachers worldwide towards large classes. Such an attitude is the result of the fact that large classes most often give rise to a set of challenges and problems, certain ones of which are supposed to be too serious for 
teachers, especially those who are not experienced enough, to cope with. Described below are the most serious challenges teachers face in large classes.

\subsubsection{Weariness}

A large class is claimed to be usually physically and psychologically tiring for the teacher. Following are examples of some Tunisian secondary school teachers' complaints about large classes that can further illustrate the above assertion.

- Once I get into the classroom, and look at the crowd of students, I feel tired even before beginning the lesson.

- I get nervous even when a student turns back to talk to her or his colleague.

- Forty students; it's hellish!

- When I look at the pile of papers waiting for correction, I feel somewhat dizzy.

- Believe me, if they gave me half a salary, I would resign now.

\subsubsection{Control problem}

As noted earlier, what is likely to cause the situation to be worse is that many teachers find it very difficult to control a large class, particularly one which includes a big number of teenage low-achievers. In this context, teachers complain about aspects of disruptive behavior on the part of students, such as noise, disinterest in learning, rudeness to the teacher or peers, and absenteeism.

\subsubsection{Detrimental effect on teaching performance}

Many teachers admit that large classes have a serious effect on their teaching performance and consequently on the fulfillment of the learning objectives. Examples of what some teachers report about the issue are listed below.

- I perform much better in a small, interested class.

- I feel that students learn less than expected in a large class.

- Group and pair-work activities rarely succeed in a large class.

- A large class is not conducive to teaching and learning.

\subsubsection{Abundance of student work}

What may further affect the teacher's performance detrimentally in large classes is her or his inability to give everybody a chance to take part in all the learning activities, and also to check and evaluate all their work, especially the written work done in the classroom or given as homework assignments. Having to correct all the students' pieces of writing is wellnigh impossible for the teacher, especially as s/he has to exercise many other responsibilities of more than one type.

\subsection{How to cope with large classes}

It could be claimed that teachers can meet the challenge of large classes if they implement the following suggestions.

\subsubsection{Perceiving a large class from a positive angle}

Surmounting the challenges resulting from crowded classrooms ought to be better initiated by getting rid of the negative attitude towards such classes. This is imperative for more scores than one, one of which is that if one lives through the feeling that a large class is physically and psychologically wearying, they are very likely to end up by turning their teaching job into an unbearable lot. In this way, absenteeism may become a phenomenon among some teachers, which may lead them to be somewhat viewed as redundant by administrators and students' parents, and cause students to experience learning difficulties that will probably be hard for some of them to overcome.

Disposing of the negative attitude towards sizable classes can be carried out by simply accepting these as one normal condition of our teaching job, and mainly through holding the deep conviction that large classes do not only have disadvantages, but also benefits. It may, however, be argued that there are no real benefits of large classes. One can counter-argue such a claim by affirming that if the benefits are not apparent to every teacher, we should do our utmost to create them instead of yielding to the belief that crowded classrooms are among the circumstances that would mark 
teaching as one of the hardest jobs.

As every teacher wishes to have enough good students in each of the groups s/he teaches, one of the benefits of a large class is that it is more than likely it can satisfy such a wish. In this sense, it is a personal conviction that the more students there are in one class, the more brilliant classmates we can find among them, which can facilitate the teacher's task or make it less tiring at more than one level, one of which is via cooperative learning. Such a type of learning can be more fruitful in case there are a respectable number of bright students from whom low-achieving classmates can learn probably better and more than they do from the teacher.

In the same setting, Hess (2001) maintains that although teaching large classes is far from easy, there are certain benefits that teachers should be aware of. She voices a similar position on the above-cited benefit of large classes referring to it under the heading The teacher is not the only pedagogue (p.3). The author affirms that since there are so many levels of language proficiency, it is only natural that the more proficient learners quickly take the part of teacherassistants. She goes on elucidating that in such classes, students can learn as much from one another as they learn from the teacher. [...] Cooperation works better than competition in the large class: cross-ability grouping allows the more able learners to improve their language skills by honing their ability to explain, to state clearly, and to give effective examples, while it provides the less able with considerable support (p. 3).

Hess (2001) examines other advantages of large classes. She assumes that a large class:

- offers more chances for interaction. The fact that there are enough students makes the class infinitely more multilevel, increases the interest, energy level, and linguistic output of the whole group;

- represents a rich variety of human resources. Since, in a large multilevel class, there are a great many opinions, a great many points of reference, perhaps many cultural backgrounds, many different experiences, and many learning styles, we can make use of this wealth of dissimilarity to our advantage in creating interesting, varied, meaningful, and student-centered lessons;

- helps professional development occur naturally. Although experience with any class size helps us to develop our teaching methodology, teaching a large multilevel class compels us to invent and develop new ways of organizing material, find better ways of setting up routine tasks, and prompts us to think, create, and grow as teachers (pp. 2 - 4).

\subsubsection{Managing a class successfully}

Successful classroom management could be vital to meeting the challenges resulting from sizable classes. Managing a class successfully can be achieved through the teacher's likeable character, outstanding scientific competence, mastery of her or his subject matter, and effective teaching methodology. All these influential qualities in a class of whatever size, and even with limited resources and scarce instructional materials, can contribute a great deal to making students interested in learning, to maintaining discipline, and consequently to successful learning. Without fail, however, if some or all those qualities are lacking or deficient, a teacher will find it seriously difficult to manage even a very small-sized class. This implies that what really counts is not the class size, but how to succeed in rising to the challenges we face however serious they are.

Harmer (1998) proposes a number of recommendations that can help with successful teaching performance in large classes. Two main ones of these are the following:

- Using pair work and group work: these are important in large classes, in that they can maximize student participation;

- Using group leaders: teachers may rely on group leaders who can hand out copies, check that everyone in their group has understood a task, collect work, and give feedback.

\subsubsection{Adopting individualization techniques}

Relying on good students as group leaders and assistant teachers in large classes implies the adoption of individualization techniques for large classes, as suggested by certain ELT writers, namely Nolasco and Arthur (1994), and Sarwar (1991).

The concept of individualization as defined by Richards and Schmidt (2002) "[is] a learner-centered approach to teaching in which (a) goals and objectives are based on the needs of individual learners, [and] (b) allowances are made in the design of a curriculum for individual differences in what students wish to learn, how to learn, and the rate at which they learn." The authors go on making it plain that "individualization includes such things, as one-to-one teaching, home 
study, self-access facilities, self-directed learning, and the development of learner autonomy, since they all focus on the learner as an individual" (p. 254).

The principles of individualization imply that one principal role of the teacher's is a facilitator, and accordingly the learner is to assume a more active role in the teaching-learning process, mainly through exercising responsibility for her or his own learning. In this frame of reference, Harmer (2001) notes that individualized leaning has the following benefits, which would reduce the load of the teacher's work in a large class.

- It is likely to be less stressful for students than performing in a whole-class setting or talking in pairs or groups;

- It can develop learner autonomy and promote skills of sel-reliance and investigation over teacherdependence;

- It can be a way of restoring peace and tranquility to a noisy and chaotic situation.

\subsubsection{Self editing and peer editing of students' written work}

Peer editing is one technique that can help lighten the load of assessing students' writing exercises for the teacher. Similarly, for the sake of reducing the big amount of learners' written work the teacher has to correct, Renaud et al (2007) suggest the technique of self editing and the technique of peer editing as two procedures manifesting the adoption of individualization for teaching large classes. These are described below:

- having students work in groups to produce one piece of writing for each group. The authors explain that this fosters communication, and also decreases the number of papers the teacher will have to correct. They recommend the teacher to tell students that all the members of one group will receive the same grade, so that all of them will be interested in producing a good composition;

- having each student, for all written work, go through the process of self editing and one or two rounds of peer editing before turning in the paper (p. 14).

\section{Student disruptive behavior}

Disruptive behavior is another major challenge teachers face and complain about most, particularly in secondary school and university institutions, and often react in different ways to its various aspects. Relying on a personal experience and on that of a number of fellow teachers, common examples of student disruptive behavior include:

- behaving disrespectfully in various ways towards the teacher

- cheating at exams

- making loud noises

- talking while the teacher or another student is talking

- coming to class late

- coming to class without the necessary educational stationery

\subsection{Ways of addressing the problem}

It rests with the teacher to provide students with an environment that is favorable and conducive to learning, but being under the pressure of some learners' behavioral disruptions would make the instructor's duties seriously challenging. The query that arises, in this respect, is how the teacher ought to respond to student problem behavior.

\subsubsection{Problem behavior is often a reaction, not an isolated action}

Undoubtedly, certain reactions to disruptive behavior, particularly the diverse types of punishment many teachers often resort to are not always an optimal solution to the problem; they may sometimes make it more serious. An important step towards addressing the problem is investigating its causes and helping students as possible as one can to overcome or deal with them successfully. Within this frame of reference, it is axiomatic that students' disruptive behavior is usually the consequence of a variety of factors. Among these are psychological troubles, such as introversion, timidity, and lack of self-confidence. Instances of aspects of misbehavior that may result from these are disinterest in learning, lack of attention in class, and absenteeism.

Other factors behind student problem behavior are social problems, like poverty, parents' divorce, and orphanhood. Being a victim of any of these problems, a student may sometimes turn verbally or physically violent against 
her or his peers, behave rudely towards the teacher, or tend to infringe other school regulations in one way or another.

Student inappropriate conduct can equally be caused by some deplorable aspects of behavior on the part of the teacher, especially those in connection with her or his relationship with learners, such as lack of respect for them, favoring the more proficient students to the detriment of the less proficient ones, or sympathizing with girls at the expense of boys or vice versa.

Additionally, in a similar context, it is very likely that some students behave impudently towards the teacher in case they fault her or his personality, scientific knowledge, teaching methodology, or professional integrity. In a word, it is accordingly a reasonable inference that student misbehavior may often be a justifiable reaction to a large extent rather than a mere incidental action. In that case, it is unwise to respond to such a reaction by a different unfavorable reaction on the part of the teacher, which may cause the situation to be worse, but alternatively by a sensible action. Putting it plainly in other terms, it is really adverse to frequently resort to punitive measures or have recourse to applying school rules whenever a student goes astray.

In general, the wisdom of working out the predicament ought to be through a range of sensible ways. Instances of these are described below.

\subsubsection{Applying a 'prevention is better than cure' principle}

A distinguishing characteristic of a successful teacher is her or his taking a "prevention is better than cure" measure in respect of the various challenges s/he or students may face in the course of the teaching-learning process. If, however, a problem or difficulty arises, s/he ought to look for reasonable ways that enable the teacher or the learners to cope with it. As regards student inappropriate conduct, the aforementioned measure lies in the teacher's having every intention of avoiding it to occur - as suggested in the Introduction - especially if it is the consequence of the teacher's unacceptable behavior towards learners, and trying her or his best to curb its motives as possible as s/he can in case it may result from other factors.

\subsubsection{Avoiding punishment}

In case a student behaves improperly, the teacher should not have recourse to punitive measures, but composure during or just after the exhibition of misconduct, as well as talking over the incident amicably with the student at a later time should be the most sensible responses. Following is a personal experience by an EFL teacher, which can prove the fruitfulness of the mentioned responses to student disruptive behavior.

Mattheoudaki (2001) in an article entitled Discipline - a flexible approach reports that one day, one of her students started a routine activity, on which he was always keen, with some sarcastic, ironic remarks, and followed these with obscenities and offensive language. She goes on recounting that when she intervened and asked him to conclude his speech and sit down, he turned his back on the class and her and walked out of the classroom. The teacher states that she thought for a couple of minutes and continued with her lesson without making any comments on the incident. She adds that when she talked with the student later that day, she found out that his parents had just divorced, and as an only child in the family, he was having a hard time. The following day, the teacher reports, the student apologized both to his classmates and to her.

Mattheoudaki (2001) draws an inference from the above incident maintaining that our reaction must always be seen in relation to particular incidents and students. She suggests that before we react, we should take a step back, examine the choices we have as well as the possible consequences of our choice. She goes on stating that before thinking about our status, we should think about our students' interests, and that our status is at stake only when we become unfair to them and lose their trust.

\subsubsection{Refraining from being too lenient or too severe}

It has been noticed that many teachers tend to be very lenient with students aiming at acquiring their liking and respect, whereas a number of others incline to be rather severe intending mainly to maintain discipline. Nevertheless, behaving frequently in either case is far from attaining the desired mentioned goals.

Leniency ought not to be a constant teacher pattern of behavior, so that it will not lead to some type of anarchy during lessons, and will not cause students to behave disrespectfully towards the teacher. It is recommended to bear in mind the English saying familiarity breeds contempt, from which we can adopt the principle constant leniency is no 
successful policy. On the other alert, consistent severity is highly inadvisable. It is psychologically accounted for as a form of violence, which may engender another kind of violence against the teacher and/or a negative attitude towards her or his subject matter. The teacher should, therefore, behave in a middle-of-the-road way towards students, which can guarantee a relationship based on mutual respect between both parties.

\subsubsection{Enlightening students about the necessity of behaving properly}

One other recourse that can help maintain discipline is raising students' awareness of the necessity of proper conduct. Playing the role of an educator, the teacher is recommended to sensitize students that they come to school not just to study school subjects and acquire academic knowledge from them, but also to learn civility, and hence how they should behave at educational institutions and somewhere else, and act as civilizing influence on those having no manners.

\subsubsection{Rewarding appropriate behavior}

Perhaps one simple, but motivating measure that can promote appropriate behavior among students is rewarding it. These can be verbal and material, and should be compatible with students' age and affective interests. Concerning verbal rewards, they can be in the form of various praising expressions whenever a student behaves properly. Material rewards may be prizes. At the end of each term, and during the-end-of-academic-year party, the best-behaved student in each class may be awarded prizes, and the best-behaved student in the whole institution may be given a more valuable award. Such a measure can further sensitize students to the necessity of good behavior, and may also create a sense of competition among them in this regard, which can consequently produce desirable results.

Following are several ways that can foster appropriate behavior through rewards as recommended by Akin-Little et al (2004), Brophy (1981), and Cameron and Pierce (1994).

- Use small rewards frequently, rather than large rewards infrequently;

- Deliver rewards quickly after the desired behavior is exhibited;

- Reward behavior, not the individual, and communicate to students the specific behavior that led to the reward;

- Use several different kinds of rewards selected carefully to ensure that they are reinforcing students.

In a related context, Gordon (1996) advises teachers to use the element of surprise, for example by giving a double reward unexpectedly, and warns them not to take rewards back.

\subsubsection{Using school rules as means of cooperation}

Teachers are reminded and students need to be aware that school rules and regulations should not merely be used as tools of punishment against students, and solely as means to protect the teacher and preserve her or his status, but as Mattheoudaki (2001) contends, they are to facilitate cooperation between both parties.

It is worthy of note that the teacher ought to draw the learners' attention that one reason behind a number of students' intention to breach school regulations and rules is that they feel they are imposed on them and are against them. A practical way through which the teacher can overcome such an adverse attitude, and can subsequently help maintain discipline is a suggestion by Renaud et al (2007). This is described below.

Ask small groups of students at the beginning of the year to write down rules they think are reasonable regarding classroom behavior and the consequences for breaking them. Collect them and summarize them on a large sheet of paper. In the next class, ask students to consider the rules and make suggestions for change. Finally, ask them to vote to accept the rules, and make a final copy to be hung in the classroom for the year.

The authors affirm that "if the rules come from the students, and they consider them to be fair, they will be more willing to follow them" (pp. 13-14).

\section{Conclusion and Recommendations}

It is generally contended, especially among teachers that teaching small-sized groups of learners is far easier and comfortable than teaching large groups. But, due to weak budget, lack of teaching space, and shortage of human resources, large classes are common in almost all educational institutions. Such classes pose a formidable challenge for teachers by reason of the various difficulties they give rise to. Another daunting challenge that is mainly the result of emotional, psychological, and social factors, and which may add insult to injury, equally for the teacher's part, is student 
disruptive behavior. However, however serious these challenges are, the instructor ought not to yield to them; s/he should always believe in her or his potentiality for success. Large classes should be viewed from a positive perspective through making them advantageous in diverse ways. One of these is that teachers, school administrators, students, and their parents should all collaborate in applying the principles of individualization in sizable groups of learners, so that the problems and difficulties resulting from large classes can be surmounted, and thereby a respectable rate of success of the teaching-learning process can be achieved. With regard to student problem behaviors, the first step towards meeting this challenge is that the parties involved ought to identify their diverse causes and try to prevent their occurrence, or in case they have occurred, they should take down-to-earth, proactive courses of action to deal with them successfully. On the other hand, it is highly recommended to introduce the issue of how to cope with large classes and meet the challenge of student inappropriate conduct in pre-service and in-service teacher training. It is also strongly advisable to order the study of educational psychology in the teaching practice syllabus.

In a nutshell, large classes cannot disappear from educational scenes, and so might student disruptive behavior. Therefore, both issues should be deemed to be part of our teaching job, and ought to be perceived as being among the prices of our success as teachers.

\section{References}

Akin-Little, K., Eckert, T., Lovett, B., \& Little, S. (2004). Extrinsic reinforcement in the classroom: Bribery or best practice. School Psychology Review, 33, 344-62.

Ali, A. \& Gracey, D. (2013). Dealing with student disruptive behavior in the classroom - A case example of the coordination between faculty and assistant dean for academics. The Journal of Issues in Informing Science and Information Technology, 10, 1-15.

Brophy, J. (1981). On praising effectively. Elementary School Journal, 81, 268-78.

Cameron, J., \& Pierce, W. (1994). Reinforcement, reward, and intrinsic motivation: A meta-analysis. Review of Educational Research, $64,363-423$

Charles, C. M. (1999). Building classroom discipline. New York: Addison Wesley Longman, Inc.

Cleveland, L.G. (2002). That's not a large class; it's a small town: How do I manage? In C. A. Stanley \& M.E. Porter (Eds.), Engaging large classes (pp. 16-27). Bolton, MA: Anker.

Epstein, M., Atkins, M., Cullinan, D., Kutash, K., \& Weaver, R. (2008). Reducing behavior problems in the elementary school classroom: A practice guide. Washington, DC: National Center for Education Evaluation and Regional Assistance, Institute of Education Sciences, U.S. Department of Education. [Online] Available: http://ies.ed.gov/ncee/wwc/publications/practiceguides (September, 2008)

Gordon, G. (1996) Managing challenging children. Ireland: Prim-Ed Publishing.

Harmer, J. (1998). How to teach English. London: Addison Wesley Longman.

Harmer, J. (2001). The practice of English language teaching. (3rd Ed.). Harlow: Pearson Education Ltd.

Hess, N. (2001). Teaching large multilevel classes. Cambridge: Cambridge University Press.

Jawitz, J. (2013). Large-class pedagogy: Interdisciplinary perspectives for quality higher education (1st Ed). In D.J. Hornsby, R. Osman, \& J. De Matos-Ala (Eds.), The challenges of teaching large classes in higher education in South Africa: A battle to be waged outside the classroom (pp. 137 - 146). Sun Media Metro.

Jungic, V, Kent, D, \& Menz, P. (2006). Teaching large math classes: Three instructors, one experience. International Electronic Journal of Mathematics Education, 1, 1- 15.

Kerr, A. (2011). Teaching and learning in large classes at Ontario universities: An exploratory study. Toronto: Higher Education Quality Council of Ontario.

Kuhlenschmidt, S. L., \& Layne, L. E. (1999). Strategies for dealing with difficult behavior. New Directions for Teaching and Learning, 77, 45- 57.

Mattheoudaki, M. (2001). Discipline - a flexible approach. Modern English Teacher 10, 45 - 47.

Nolasco, B. and L. Arthur (1994). Large classes. Prentice Hall International (UK) Ltd.

Renaud, S., Tannebaum, E., \& Standal, P. (2007). Student-centered teaching in large classes with limited resources. English Teaching Forum, 45, 12-18.

Richards, J. C \& Schmidt, R. (2002). Longman dictionary of language teaching and applied linguistics (3rd Ed.). Harlow: Pearson Education Limited.

Sarwar, Z. (1991). Adapting individualization techniques for large classes. English Teaching Forum, 29, 16 - 21.

Sorcinelli, M.D. (1994). Dealing with troublesome behaviors in the classroom. In K.W. Prichard \& R.M.Sawyer (Eds.), Handbook of college teaching: Theory and applications (pp. 365-373). Westport, CT: Greenwood Press.

Sulistyowati, T. (2012). Making large classes smaller: The challenge of teaching English to young learners in Indonesia. Proceeding the 2nd National Conference on Teaching English for Young Learners in Indonesia (TEYLIN): TEYLIN: From policy to classroom. (pp. 162-170)

Todd, R. W. (2006). Why investigate large classes? KMUTT Journal of Language Education, 9, 1-12.

Topper, K., Williams, W., Leo, K., Hamilton, R., \& Fox, T. (1994). A positive approach to understanding and addressing challenging 
behaviors: Supporting educators and families to include students with emotional and behavioral disorders in regular education. Burlington, VT: The University Affiliated Program of Vermont. Center for Developmental Disabilities.

UNESCO (2006). Practical tips for teaching large classes: A teacher's guide. Bangkok, Thailand.

Ur, P. (1996). A course in language teaching: Practice and theory. Cambridge University Press.

Wolne, D. (2011). Challenges and benefits of large enrollment classes. Office of Support for Effective Teaching. 